\title{
THE INFLUENCE OF TRAUMA UPON THE ONSET OF INTERSTITIAL KERATITIS*
}

BY

\section{T. Harrison Butler}

\section{BIRMINGHAM}

THE relationship of an accident or a trivial trauma to interstitial keratitis has received little attention in this country, but it is a question of the greatest importance from the point of view of the Workmen's Compensation Act. I have been through several years of the volumes of THE OPHTHALMOSCOPE and THE BRITISH JOURNAL OF OPHTHALMOLOGY, and I have found practically nothing bearing on the subject. German statistics admit that in about 3 per cent. of cases there is a history of an accident, but there is a tendency to regard the trauma rather as a coincidence than as a causal factor.

I personally had no idea that there was any such causal relationship till the matter was brought to my notice by a paper read by $\mathrm{Mr}$. Coulter at the Oxford Congress. This will be found in the British Journal of Ophthalmolgy, Vol. II, page 139. $\mathrm{Mr}$. Coulter could find but three references in the literature referring to the subject. When I heard the paper I remembered that I had seen more than one case of interstitial keratitis in which I had obtained a history of an accident, but I had regarded the association as merely a coincidence or, at any rate, a rare determining cause.

At the recent Congress of the Ophthalmological Society in London, Mr. Cunningham read a very interesting statistical paper upon the disease, and he found a history of accident in 3 per cent. of his cases. In the discussion which followed, Mr. Spicer stated that he thought that 3 per cent. agreed with his experience. I think, then, that we may take it that the general opinion of ophthalmologists is that about 3 per cent. of all cases give a history of accident.

After hearing Mr. Coulter's views, and those expressed in the discussion of his paper I gave special attention to the matter, and at the Birmingham Eye Hospital we found case after case coming up with a history that the attack had been brought on by an accident. I have had to report on three or four of them for compensation.

One of the very first cases of the kind was operated upon by me some ten years ago for senile cataract. After the operation an opacity appeared in the centre of the cornea, and this developed

- Read on June 13 to a meeting of the Midland Ophthalmological Society at Shrewsbury. 
into a severe attack of interstitial keratitis with irido-cyclitis. The eye was eventually removed. A careful examination of the other eye showed unmistakable evidence of a past interstitial keratitis, and I got a history of inflammation in childhood. It is obvious that the trauma caused a recrudescence of the inflammation.

Then a case was admitted to the Birmingham Eye Hospital under Mr. Wood White. A foreign body had been removed from the cornea and shortly afterwards severe interstitial keratitis developed and rapidly appeared in the second eye. I reported to the insurance company that they would have to admit liability.

After returning from the London Congress I thought that it would be instructive to find out from my hospital notes what my exact percentage was. At the Coventry Hospital I keep an index of diseases. This is made by the Sister, and she uses her discretion as to what she enters. Probably not more than half of the cases have been entered, because some of the Sisters have considered that the condition is too common to take note of. I turned out the card and got the porter to get me all the case sheets that he could find during the past ten years. I wish to emphasize the fact that for half this period I had not the question of accident in my mind, and so in many cases no question was asked about the possibility of any accident; for this reason I am certain that the percentage given is too low. This is borne out by the fact that the total cases give a percentage of about 14, whereas the later cases give a percentage of 25 .

I have divided the patients into two groups: school age and infants, under 14 ; and industrial age, over 14.

I get the following figures:

Over 14-26 cases: 4 accidents, and 2 factors which may be regarded as accidents-one man had been gassed in the war and the disease followed the gassing; and in another the inflammation began after an operation for an empyema of the antrum which followed scarlet fever. This gives a percentage of $15 \cdot 3$ for actual accidents, and 23 per cent. if the other incidents are included.

Under 14-Here we should not expect to find evidence of trauma and I was surprised to discover it.

There were 31 cases. I found four accidents, a percentage of 13 . One followed the instillation of atropin at the school clinic, and another followed an operation for tonsils and adenoids. This gives a percentage of 20 , including all incidents.

It is interesting that two cases followed an operation in the face region, and I think that this cannot be regarded as a mere coincidence. The atropin case may be such, but I think that it is not. The child came to the school clinic with normal clear corneae. A week later she developed. severe keratitis in both eyes of the typical interstitial variety. 
In all we have 59 cases, and in 12 there was a trauma or an operation-20 per cent.

I do not think that these cases are in any way exceptional ; they came in the ordinary routine of hospital work, and in the majority no questions were asked about any trauma. I am strongly inclined to the view that at least 20 per cent. of all cases are directly induced by a trauma, acting upon an eye which contains the spirochaeta pallida in the cornea.

I have selected a few of the most interesting examples.

P.J.B., aged 11. Came to the Coventry Hospital on April 21, 1915. A week previously she had received a blow upon the left eye. She showed typical interstitial keratitis with a muddy iris and severe photophobia. She had had a "rest cure" at a sanatorium for tuberculosis. She was admitted. On Sept., 1916, she had a relapse in the same eye. The cornea was oedematous and there was severe iritis. Unfortunately no Wassermann test was made, and it is probable that this case was tuberculous in nature. There is no note of any signs suggesting syphilis.

I.M., aged 4. Came to the Hospital on May 3, 1922. A month ago she was scratched by a cat all down the right side of the face. Next day she fell upon a spade causing a wound at the outer canthus upon the lids. There is a recent scar in this situation. A few days later the eye became inflamed and in a week the other eye followed. There is a typical interstitial keratitis. The mother had three dead children and then this child was born.

A.E.P., aged 15. Date of treatment, February 18, 1918. After an accident of a trivial nature interstitial keratitis appeared in the left eye. Hutchinson's teeth. Wassermann: positive. May, 1919, very much better. *July, 1922. Has had a bit of steel removed from his right eye, three weeks later developed severe interstitial keratitis in this eye.

A.H.S., aged 29. First seen, November 7, 1918. About a month ago got a little green paint in his right eye. 14 days later the eye began to get red. Now has a typical interstitial keratitis chiefly in the lower segment of the cornea. 'Ihree brothers and sisters died under one year old. Wassermann : positive.

H.O., aged 21. First seen October 30, 1918. On September 25, an electric lamp bulb burst when she was exhausting it and some of the glass got into the left eye. On October 19, the left eye began to get inflamed. I found that she had typical interstitial keratitis in the injured eye, and that the right eye showed traces of the same disease. Her mother had contracted syphilis pefore marriage and 11 babies had died soon after birth before the birth of this patient. (Compensation case.) 
G.C., aged 21. First seen by me May 3, 1911. 14 days ago some sand entered the left eye. He now has interstitial keratitis with acute iritis. The case is particularly interesting in that it would seem to suggest that an accident to one eye can precipitate an interstitial keratitis in its fellow.

F.M., aged 13. First seen April 10, 1911. On April 4, he had a blow upon his glasses with a stick and the broken glass wounded the right eye. The cornea showed a long incision which passed into the sclera. The eye was removed on April 5. On May 22 he came to the Hospital complaining that the sight of the left eye had been deteriorating for three weeks. He was found to have interstitial keratitis with circumciliary injection and iritis. The vision was $6 / 60$. The child had Hutchinson's teeth. Curiously enough this case turned up on June 12,1922, after an interval of 11 years. The eye now has vision of $6 / 60$ ths. There is a central corneal nebula and old bleached synechiae posteriores. There is an anterior choroiditis and some diffuse general choroidal change.

In a certain number of cases an accident to the cornea may cause a diffuse infiltration of the cornea which may affect the deeper layers and cause a keratitis profunda. This must be distinguished from the typical interstitial keratitis of syphilitic or tuberculous origin. I have a compensation case of this nature in hand at the present time.

B.S., aged 30. First seen June, 1921. On March 20 a bit of brass hit the right cornea. An ulcer formed and he was admitted to the Birmingham Eye Hospital on April 5 and discharged on April 28 with a small thin central nebula. I examined him and reported that he had good acuity in each eye and that there was no loss of wage earning capacity. On May 7 there was a recrudescence of the ulceration and he was ultimately left with a dense scar involving half the cornea.

The interesting part of the history is that an ophthalmic surgeon has reported that he is suffering from interstitial keratitis, and that if he returns to work the slightest injury or abrasion may cause the same train of symptoms in the sound eye.

The man gave negative Wassermann and von Pirquet reaction. $\mathrm{He}$ has never had syphilis, and his mother has given birth to no dead babies and there have been no miscarriages. He is suffering from a scar from a recurrent corneal ulcer.

The facts that I have brought before you seem to suggest the following conclusions :-

(1) An attack of interstitial keratitis may be precipitated by an accident to a cornea which is disposed to the disease by syphilis or tubercle.

(2) It is possible that a very slight trauma such as the instilla- 
tion of drops or the irritation of a general anaesthetic may have the same effect.

(3) The attack in the injured eye is liable to be followed by interstitial keratitis in the uninjured eye.

(4) It is possible that an injury to one eye may cause interstitial keratitis in the other eye.

(5) The question may be asked: " is it not possible that in every case of interstitial keratitis the attack is precipitated by some slight trauma?"

I am fully aware that the number of cases I have worked upon is small and I regard this as merely a preliminary paper. The house surgeon at the Birmingham Eye Hospital is going to continue the investigation upon the vast material at our command at the Birmingham Eye Hospital, and I shall await with great interest the result of his labours.

\section{PAPILLOEDEMA*}

BY

\section{J. Lockhart Gibson, M.D.Edin., M.R.C.S.Eng.} BRISBANE

PAPIlloedema, as contra-distinguished, for instance, from albuminuric retinitis, which is a neuro-retinitis, is caused by increased intra-cranial tension. Increased intra-cranial tension is produced either by an intra-cranial new growth, by an intra-cranial inflammatory condition, or by some poison, chemical or microbic, circulating in the blood.

It appears to me that poisons, when they set up increased intracranial tension, do so by irritating the choroid plexus or gland, and exciting it to secrete excessively. In my experience papilloedema has been an indication of one of the following things in the order given. Plumbism in children; intra-cranial gummatous meningitis or gumma; glioma of the brain; sub-dural or cerebral abscess due to middle ear disease or other infection.

Victor Horsley's researches indicate that a cause of sudden and even fatal increase of intra-cranial tension is a severe blow on the head, and that in such cases immediate trephining for relief of tension may save life. Might not immediate lumbar puncture do as well? I have had no experience of intra-cranial hydatid.

I have seen and treated very many cases of papilloedema in children below 8 years of age, due to plumbism. Papilloedema

* Contribution to Discussion at Australian Medical Congress, Brisbane, August, 1920. 